\title{
The widened scope of plant and soil and the future of opinion papers
}

\author{
Hans Lambers
}

Published online: 13 August 2020

C) Springer Nature Switzerland AG 2020

Plant and Soil continues to be the leading journal when it comes to publishing articles that enhance our mechanistic understanding of plant-soil interactions. It has long been our policy to reject manuscripts that do not explicitly focus on this mechanistic understanding, but covered agronomy, plant nutrition or ecology. This is about to change.

From now onwards, we will consider manuscripts that deal with plant nutrition, agronomy or ecology that shift our fundamental understanding of plant production systems. They will have to be of outstanding quality. Simple fertiliser trails, which are valuable in plant nutrition and ecological research in their own right, will still not be considered.

Quite some time ago, we had a category we called 'Opinion Papers'. When it turned out that there was little to no interest in this category, we discontinued it. In the recent past, however, there has been an upsurge of interest in this category, and we will soon start publishing Opinion Papers again. Unlike Commentaries, which are by invitation only, Opinion Papers are unsolicited, but we recommend authors to contact the Editor in Chief to check if the subject falls within the scope of Plant and Soil.

Hans Lambers

Editor in Chief

Publisher's note Springer Nature remains neutral with regard to jurisdictional claims in published maps and institutional affiliations.
H. Lambers $(\bowtie)$

School of Biological Sciences, University of Western Australia, Perth, WA 6009, Australia

e-mail: hans.lambers@uwa.edu.au 